\title{
The Ambulatory Care Score For Atrial Fibrillation: A Decision-Support For Triage of New-Onset Atrial Fibrillation Without Cardiologist's Opinion; A Derrivation Study
}

\section{Constance Michiels}

Roubaix General Hospital

François Outteryck

Roubaix General Hospital

Perrine Libert

Roubaix General Hospital

Karine Bauley

Roubaix General Hospital

Carole Godesence

Roubaix General Hospital

Rémy Diesnis ( $\nabla$ remy.diesnis@ch-roubaix.fr)

Roubaix General Hospital

\section{Research Article}

Keywords: atrial fibrillation, triage, decision-support, score

Posted Date: February 2nd, 2022

DOI: https://doi.org/10.21203/rs.3.rs-1174697/v1

License: (c) (i) This work is licensed under a Creative Commons Attribution 4.0 International License.

Read Full License 


\section{Abstract}

Background: As the population ages, the prevalence of atrial fibrillation (AF) is increasing. This leads to significant healthcare resource use - mainly the cost of hospitalization. Using guidelines, we built the Ambulatory Care Score for Atrial Fibrillation (ACSAF) for application in emergency departments (EDs) that lack a cardiologist. The primary objective of the present study was to validate the ACSAF for the triage of new-onset AF (NOAF) by comparison with the cardiologist's opinion.

Methods: This single-centre, prospective, observational, comparative study was performed at a general hospital between November 2018 and October 2019. All adult patients with NOAF were included. Patients with a systolic blood pressure $<80 \mathrm{mmHg}$ or a heart rate $>180 \mathrm{bpm}$ were excluded. The ACSAF was calculated by an ED physician in blind to the cardiologist's opinion. The primary outcome was the mean difference in the ACSAF between ambulatory care group and the hospital care group. A receiver operating characteristic (ROC) curve was plotted to determine the optimal cut-off for the ACSAF.

Results: 81 patients with NOAF (42 men (51.9\%); mean age: $69 \pm 16$ years old) were included in the study. The mean ACSAF was higher in the hospital care group $(2.16 \pm 1.05)$ than in the ambulatory care group $(1.03 \pm 0.97 ; p<0.0001)$. The optimal ACSAF cut-off was 2 , giving a sensitivity [ $95 \%$ confidence interval] of $71.4 \%[57.1-83.7]$ and a specificity of $81.2 \%[68.8-93.8]$.

Discussion \& Conclusion: The ACSAF enables ED physicians to decide on the triage of NOAF in the absence of a cardiologist's opinion.

Trial registration: ANSM (French Drug Administration) : ID RCB 2018-A01800-55 French National Data Protection Commission (Commission nationale de l'informatique et des libertés (Paris, France); reference: MRC-003 2197970, June 2nd, 2018)

\section{Introduction}

Atrial fibrillation (AF) is an irregular supraventricular tachycardia characterized by anarchic, rapid (400600 beats per minute) electrical activity of the atria and thus a loss of hemodynamic efficacy. This rhythm disorder is caused by automatic, ectopic foci within the atria or parts of the pulmonary veins and by a large number of small reentrant circuits associated with areas of fibrosis.

Atrial fibrillation is the most frequent type of sustained arrhythmia, with an estimated prevalence in the general population of 1 to $2 \%(1)$. With population aging, the prevalence of $\mathrm{AF}$ has increased significantly in recent years (by about 5\% a year between 1993 and 2007) (2). It has been estimated that by 2030, there will be 14 to 17 million patients with AF in the European Union and 120,000 to 215,000 new diagnoses per year(3). These new cases lead to a significant consumption of healthcare resources - the cost of hospitalization, primarily. 
In 2017, we evaluated the Ambulatory Care Score for Atrial Fibrillation (ACSAF) in a retrospective feasibility study; we observed a significant difference in the mean \pm standard deviation (SD) ACSAF between hospitalized patients and ambulatory care patients $(1.96 \pm 1.22$ and $0.46 \pm 0.67$,

respectively) (4). The eight-item ACSAF is based on guidelines issued by the French Society of Cardiology (SFC) and the French Society of Emergency Medicine (SFMU) (1) (Table 1). The score's purpose is to facilitate initial ambulatory care of a patient with new-onset AF (NOAF) in the absence of a cardiologist's opinion. When the ACSAF is below a certain cut-off, the emergency department (ED) physician can initiate treatment of $A F$ in the ED and propose ambulatory care and a fast-track consultation with a cardiologist. In contrast, a ACSAF above the cut-off would lead to hospital admission, an assessment by a cardiologist, and the initiation and monitoring of appropriate in-hospital treatment. It should be noted that the score focuses on patient triage and does not provide any guidance on the choice of treatments.

The primary objective of the present study was to evaluate the ACSAF prospectively by comparing patients referred for ambulatory care with patients hospitalized following an assessment by a cardiologist. The secondary objectives were to define a positivity cut-off for the score and to compare the groups' follow-up status (assessed in terms of the proportions of patients having consulted a cardiologist and having been readmitted to hospital) 3 months after the ED visit.

\section{Materials And Methods}

Study design

We performed a 12-month prospective, quantitative, comparative, derrivation study between November $1^{\text {st }}, 2018$, and October $31^{\text {st }}, 2019$, in the ED at Roubaix General Hospital (Roubaix, France).

This study was approved by an independent ethics committee (CPP Ile-de-France III, Paris, France; reference: ID RCB 2018-A01800-55) and registered with the French National Data Protection Commission (Commission nationale de l'informatique et des libertés (Paris, France); reference: MRC-003 2197970, June $2^{\text {nd }}, 2018$ ).

We included all adult patients (aged 18 and over) admitted to the ED at Roubaix General Hospital and whose ECG showed NOAF, regardless of the indication and reason for admission to the ED. The exclusion criteria were late-stage dementia (ruling out the provision of informed consent) and poorly tolerated AF (systolic blood pressure below $80 \mathrm{mmHg}$ or a heart rate over $180 \mathrm{bpm}$ ). The primary efficacy criterion was the difference in the mean ACSAF between the ambulatory care group and hospital care group.

The secondary efficacy criteria were a receiver operating characteristic (ROC) curve to determine the optimal ACSAF cut-off, the proportion of patients having consulted a cardiologist within 3 months of the ED visit, the time interval between discharge from the ED and consultation with a cardiologist, and proportion of patients having been readmitted to hospital within 3 months of the ED visit. 
Data were collected using a standardized case report form filled out by the attending physician in the ED. After having been provided with comprehensive information on the study and its objectives by a senior ED physician, each patient was asked for his/her verbal informed consent to participation approved by the ethics committee. A copy of an ECG recorded concomitantly was attached to the case report form.

A full set of laboratory tests was prescribed by the ED physician on the day of the patient's ED visit. The laboratory data required for an initial assessment of NOAF were specified, in order to standardize the prescriptions. These biological outcomes were collected retrospectively by the study's principal investigator.

The ACSAF, $\mathrm{CHA}_{2} \mathrm{DS}_{2}$-VASc and HAS-BLED scores were calculated retrospectively on the day of the ED visit by a study investigator. The investigator calculating the ACSAF was blinded to the triage decision made jointly by the cardiologist and the ED physician. This triage decision was considered as the gold standard. We contacted each patient by phone 3 months after the ED visit, in order to determine whether he/she had consulted a cardiologist and/or had since been readmitted to hospital.

\section{$\underline{\text { Statistical analysis }}$}

Based on the sensitivity and specificity calculated in our preliminary study, we estimated the sample size required to obtain a precision of 0.2 with an ACSAF cut-off of 0 or 1 . The largest estimated sample size was $n=80$ patients. The threshold for statistical significance was set to $p<0.05$ in all analyses. Qualitative variables were reported as the frequency with percentage and confidence interval (Cl). Quantitative variables were reported as the mean $\pm S D$. We used Student's test to compare mean values and the chisquared test to compare frequencies. Lastly, we plotted a ROC curve in order to calculate the $95 \%$ confidence intervals (Cls) for the sensitivity and specificity at each cut-off value.

\section{Results}

Of the 95 eligible patients, 14 were not included in the analysis (Figure 1). A total of 53,310 patients had been admitted to the ED during the study period; hence, the prevalence of NOAF was $0.15 \%$. Of the 14 patients not included, 9 were not included prospectively by the attending ED physician but had been identified retrospectively by their primary or associated diagnostic codes (according to the International Statistical Classification of Diseases and Related Health Problems, $10^{\text {th }}$ Revision). Five patients were excluded for medical reasons: recurrence of $A F(n=3)$, flutter $(n=1)$, and focal atrial tachycardia $(n=1)$.

Hence, we included 81 consecutives patients (42 men (51.9\%) and 39 women (48.1\%)). The mean \pm SD age was $69.2 \pm 16.0$. Thirty-two of the included patients were discharged to home (forming the ambulatory care group) and 49 were immediately transferred to a hospital ward (forming the hospital care group).

All the significant differences between the ambulatory care and hospital care groups were related to one or more ACSAF items (Table 2). Fifty-six of the 81 included patients $(70.9 \%)$ had an indication for 
anticoagulation, i.e. a $\mathrm{CHA}_{2} \mathrm{DS}_{2}$-VASc score $\geq 1$ (17 patients (53.1\%) in the ambulatory care group and 39 patients $(83 \%)$ in the hospital care group; $p=0.009)$. Six patients $(7.4 \%)$ had a significant haemorrhagic risk, i.e. a score HAS-BLED ${ }^{3} 3$ (3 patients $(9.4 \%)$ in the ambulatory care group and 3 patients $(6.1 \%)$ in the hospital care group; $p=0.68$ ). The ACSAF was calculated retrospectively by the study's principal investigator, who was blinded to the decision taken jointly by the ED physician and the cardiologist on the day of the ED visit. The mean \pm SD ACSAF was $1.03 \pm 0.97$ in the ambulatory care group and $2.16 \pm 1.05$ in the hospital care group $(p<0.0001)$ (Figure 2$)$.

We calculated the sensitivity and specificity for each ACSAF cut-off (Table 3). The optimal cut-off for the ACSAF was 2, with a sensitivity [95\% Cl] of $71.4 \%$ [ $57.1 \%-83.7 \%]$ and a specificity $[95 \% \mathrm{Cl}]$ of $81.2 \%$ [68.8\%-93.8\%]. The area under the ACSAF ROC curve [95\%CI] was 79.4\% [69.5\%-89.3\%] (Figure 3).

The score's performance was measured with regard to a "gold standard": the cardiologist's opinion on the type of management. Sixty-nine patients (30 in the ambulatory care group and 39 in the hospital care group) were contacted by phone 3 months after their visit to the ED. Twenty-seven patients (90\%) in the ambulatory care group and $23(59 \%)$ in the hospital care group had consulted a cardiologist $(p=0.0096)$. The mean time interval between discharge from the ED and consultation with a cardiologist was $66.3 \pm$ 62.6 days in the ambulatory care group and $56.4 \pm 45.7$ days in the hospital care group $(p=0.55)$. Three patients $(10.3 \%)$ in the ambulatory care group and 17 patients $(43.6 \%)$ in the hospital care group had been readmitted to hospital $(p=0.0068)$.

\section{Discussion}

With regard to the study's primary objective, the ACSAF appears to be of interesting in the triage of cases of NOAF in the absence of a cardiologist's opinion in the ED.

Overall, the ambulatory care and hospital care groups were similar with regard to most demographic, clinical and biochemical characteristics. However, there were some significant differences. The mean age was significant greater in the hospital care group $(73.5 \pm 15.3)$ than in the ambulatory care group (62.6 \pm $15.0 ; p=0.002$ ) (Table 2). Independently of co-morbidities, age is one of the main risk factors for NOAF. Overall, our study population was young. In a study of patients in the United States between 1993 and 2004, McDonald et al.(5) compared the characteristics of patients with AF who were hospitalized (or not) after their visit to the ED. The mean $[95 \% \mathrm{Cl}]$ age was $68[65-70]$ in the non-hospitalized group and 69 [67-71] in the hospitalized group (5).

The N-terminal fragment of brain natriuretic peptide prohormone (NT-proBNP) is a biomarker of cardiac dysfunction. A high plasma concentration of NT-proBNP is suggestive of heart failure - essentially when the patient does not present major clinical signs and/or an echocardiogram is not immediately available. In an acute context, the upper normal limit for NT-proBNP is $300 \mathrm{pg} / \mathrm{mL}(6)$. However, an elevated NTproBNP level may be associated with several cardiovascular or non-cardiovascular factors or pathologies (including AF, age, and kidney failure) and so may not always be easy to interpret (7). In the present study, 
we observed a significant $(p<0.001)$ difference in the mean blood NT-proBNP level between the ambulatory care group and the hospital care group (Table 2).

An $\mathrm{AF}$ trigger was more prevalent in the hospital care group than in the ambulatory care group $(p=0.05)$ (Table 2). The presence of a triggering factor and/or an associated disease was therefore linked to a greater risk of hospitalization. This finding is in line with McDonald et al.'s observation of an association between congestive heart failure and a greater risk of hospitalisation(5).

With regard to the clinical scores, we found a significant intergroup difference in the mean $\mathrm{CHA}_{2} \mathrm{DS}_{2}-\mathrm{VASc}$ score $(p=0.009)$ but not in the mean HAS-BLED score $(p=0.14)$ (Table 2$)$. In a study performed in Thailand between 2005 and 2010 (8), Apiyasawat et al. sought to determine whether the $\mathrm{CHA}_{2} \mathrm{DS}_{2}$-VASc score was a predictive factor for mortality after hospitalization for AF. The hospitalization rate for AF was 15.5 per 100,000 people per year. The two main co-morbidities were arterial hypertension and diabetes. The mean $\pm \mathrm{SD} \mathrm{CHA}{ }_{2} \mathrm{DS}_{2}$-VASc score for the 8981 hospitalized patients was $1.79 \pm 1.4(\mathrm{p}<0.0001)$. We found a similar score in our ambulatory care group. We therefore consider that the $\mathrm{CHA}_{2} \mathrm{DS}_{2}-\mathrm{VASc}$ score (which is not correlated with the HAS-BLED score) is not a hospitalization factor per se.

A history of chronic kidney disease (CKD) was not significantly associated with the risk of hospitalization for a patient presenting with NOAF. Furthermore, there was no significant intergroup difference in the mean serum creatinine level $(12.5 \pm 18.3 \mathrm{mg} / \mathrm{L}$ in the ambulatory care group vs. $10.9 \pm 4 \mathrm{mg} / \mathrm{L}$ in the hospital care group; $p=0.62$ ).

Kulkarni et al. found that the prevalence of $\mathrm{AF}$ was higher among patients suffering from CKD and that this value increased with worsening renal function (9). In fact, the prevalence of AF was $1.0 \%$ in adults with normal renal function (glomerular filtration rate (GFR) $>90 \mathrm{~mL} / \mathrm{min} / 1.73 \mathrm{~m}^{2}$ ), $2.8 \%$ for a GFR of between 60 and $90 \mathrm{~mL} / \mathrm{min} / 1.73 \mathrm{~m}^{2}$ (CKD stage 2), 2.7\% for a GFR between $60-30 \mathrm{~mL} / \mathrm{min} / 1.73 \mathrm{~m}^{2}$ (CKD stage 3), and $4.2 \%$ for a GFR between $30-15 \mathrm{~mL} / \mathrm{min} / 1.73 \mathrm{~m}^{2}$ (CKD stage 4 ). The odds ratios $[95 \% \mathrm{Cl}]$ adjusted for age, sex and race were respectively 2.67 [2.04 - 3.48], 1.68 [1.26 - 2.24], and 3.52 [1.73- 7.15].

None of our study participants had overt thyroid disorders. Hence, even though there was a significant intergroup difference in the TSH level, it did not influence the overall ACSAF. In Selmer et al.'s 2012 study of a cohort of 586,460 patients, the AF rate was $2.9 \%$ among euthyroid individuals, $4.6 \%$ among patients with hyperthyroidism, and $2.5 \%$ among patients with hypothyroidism. Despite the absence of overt thyroid disorders in our study population, the known relationship between these disorders and the risk of NOAF means that systematic screening for hyperthyroidism (as an AF trigger factor) and a comprehensive pretreatment assessment are still essential (10).

The ambulatory and hospital care groups differed significantly with regard to the ACSAF items only; this score therefore appears to be discriminant when considering the ambulatory treatment of patients with symptomatic or fortuitously discovered NOAF in the ED. In the present study, the ACSAF's sensitivity 
[95\% Cl] for a threshold of 2 was $71.43 \%$ [57.14\%-83.67\%], and the specificity was $81.25 \%$ [68.75-93.75] (Table 2). The optimal cut-off for a positive ACSAF score was therefore 2. Hence, an ACSAF ${ }^{3} 2$ should prompt hospitalization of the patient. In contrast, for a ACSAF <2, the attending ED physician can prescribe appropriate treatment (according to the European Society of Cardiology guidelines) without seeking a cardiologist's opinion. The patient can be discharged to home and then fast-tracked for a consultation with a cardiologist, which ideally should take place a week after the ED visit.

Ninety percent of the patients in the ambulatory care group consulted a cardiologist, and the mean time interval between the ED visit and this consultation was 66.3 days. Only $10.3 \%$ had been readmitted. In the hospital care group, the consultation rate (59\%) and the hospital readmission rate $(43.6 \%)$ differed significantly from the values in the ambulatory care group. Hence, ambulatory treatment does not appear to have a negative impact on patient outcomes; it was associated with a high consultation rate and a low hospital readmission rate.

Nevertheless, the time interval between the ED visit and the consultation with a cardiologist was too long; hence, the ACSAF should only be used in institutions with a fast-track follow-up program. With 32 patients in the ambulatory care group, three dedicated cardiology consultations a month would be sufficient in our institution, and so the implementation of a fast-track program appears to be feasible.

The present study had a number of strengths, including its prospective design and its high statistical power (due to the large sample size of 81). To avoid classification bias, the investigator calculating the ACSAF was blinded to the decision made jointly by the ED physician and the cardiologist on the day of the ED visit. Moreover, we limited the exclusion criteria as much as possible, so that the study population was as representative as possible of ED patients presenting with symptomatic or fortuitously discovered NOAF.

However, our single-centre study design raises the question of whether our results can be extrapolated to the general population. We did not harmonize the cardiologists' decisions in the ED. Since this decision was the "gold standard", it might have induced bias. Lastly, we did not evaluate compliance with the 2015 SFC/SFMU guidelines on standardized laboratory assessments and treatment procedures.

\section{Conclusion}

The number of consultations in the ED for AF has increased considerably in the last 10 years, and a high proportion of these patients are admitted to hospital immediately. This observation underlines the importance of a more systematic approach to the evaluation, treatment and triage of NOAF patients in the ED. Our usual practice emphasizes the importance of clinical scores. The ACSAF is a triage decisionsupport score for the ED physician dealing with cases of NOAF.

In the present study, the ambulatory and hospital care groups differed significantly with regard to the ACSAF items only. Our score appears thus to be discriminant for the ambulatory management of patients 
with symptomatic or fortuitously discovered NOAF in the ED. Following this derivation study, a multicentre validation study with standardized cardiological management would be necessary.

\section{Declarations}

Ethics approval and consent to participate: CPP Ile-de-France III, Paris, France; reference: ID RCB 2018A01800-55 approves this study. Informed verbal consent was obtained for each patient included in accordance with the French Legislation for non-interventional prospective study (Article L 1121-1 and Article L1122-1).

The study protocol is in accordance with the ethical principles established by Declaration of Helsinki in 1964 during the 18th World Medical Association and by the amendments established during all the following meetings.

Regarding to the retrospective feasibility study we reported in the introduction, informed consent is deemed unnecessary according to the French legislation because we have collected data from current practice retrospectively (Délibération no 2018-155 du 3 mai 2018). Collective information about retrospective study was is available in our hospital (poster in admission office and hall, patient welcome booklet and website). It is in accordance with the ethical principles established by Declaration of Helsinki in 1964 during the 18th World Medical Association and by the amendments established during all the following meetings too.

It was registered with the French National Data Protection Commission (Commission nationale de I'informatique et des libertés (Paris, France); reference: MRC-003 2189292, May $24^{\text {th }}, 2018$ ).

Consent for publication: Not applicable

Availability of data and materials: The datasets used and/or analysed during the current study are available from the corresponding author on reasonable request.

Competing interests: The authors have no conflicts of interests to disclose.

\section{Funding: none}

Authors' contributions: $\mathrm{CM}, \mathrm{FO}$ and RD conceived the study and designed the trial. CM and RD supervised the conduct of the trial and data collection. and undertook recruitment of participating patients and managed the data, including quality control. RD provided statistical advice on study design and analyzed the data. As head of the Emergency Department, CG chaired the data oversight committee. CM and KB drafted the manuscript, and PL contributed to its translation. All authors contributed substantially to its revision. $\mathrm{RD}$ takes responsibility for the paper as a whole.

\section{Acknowledgements}


All investigators and General Hospital of Roubaix (promotor).

\section{References}

1. Taboulet P, Duchenne J, Lefort $H$, Zanker $C$, Jabre P, Davy J-M, et al. Prise en charge de la fibrillation atriale en médecine d'urgence. Recommandations de la Société française de médecine d'urgence en partenariat avec la Société française de cardiologie. Ann Fr Médecine Urgence. 2015 Sep 1;5(4):260-79.

2. Piccini JP, Hammill BG, Sinner MF, Jensen PN, Hernandez AF, Heckbert SR, et al. Incidence and Prevalence of Atrial Fibrillation and Associated Mortality Among Medicare Beneficiaries, 1993-2007. Circ Cardiovasc Qual Outcomes. 2012 Jan;5(1):85-93.

3. Kirchhof P, Benussi S, Kotecha D, Ahlsson A, Atar D, Casadei B, et al. 2016 ESC Guidelines for the management of atrial fibrillation developed in collaboration with EACTS. Eur Heart J. 2016 Oct 7;37(38):2893-962.

4. Michiels C. Évaluation d'un score diagnostique de prise en charge ambulatoire des fibrillations auriculaires de novo sans avis cardiologique au centre hospitalier de Roubaix [Internet]. [Lille, France]: Université du Droit et de la Santé - Lille 2 -Faculté de Médecine Henri Warembourg; 2019 [cited 2020 Dec 2]. Available from: https://pepite-depot.univ-lille.fr/LIBRE/Th_Medecine/2019/2019LILUM272.pdf

5. McDonald AJ, Pelletier AJ, Ellinor PT, Camargo CA. Increasing US emergency department visit rates and subsequent hospital admissions for atrial fibrillation from 1993 to 2004. Ann Emerg Med. 2008 Jan;51(1):58-65.

6. Ponikowski P, Voors AA, Anker SD, Bueno H, Cleland JGF, Coats AJS, et al. 2016 ESC Guidelines for the diagnosis and treatment of acute and chronic heart failureThe Task Force for the diagnosis and treatment of acute and chronic heart failure of the European Society of Cardiology (ESC)Developed with the special contribution of the Heart Failure Association (HFA) of the ESC. Eur Heart J. 2016 Jul 14;37(27):2129-200.

7. Maisel A, Mueller C, Adams K, Anker SD, Aspromonte N, Cleland JGF, et al. State of the art: Using natriuretic peptide levels in clinical practice. Eur J Heart Fail. 2008 Sep 1;10(9):824-39.

8. Apiyasawat S, Tangcharoen T, Wisaratapong T, Yamwong S, Wiboonpolprasert S, Sritara P. CHA囚DSヌVASc scores predict mortality after hospitalization for atrial fibrillation. Int J Cardiol. 2015 Apr 15;185:293-6.

9. Kulkarni N, Gukathasan N, Sartori S, Baber U. Chronic Kidney Disease and Atrial Fibrillation: A Contemporary Overview. J Atr Fibrillation [Internet]. 2012 Jun 15 [cited 2019 May 27];5(1). Available from: https://www.ncbi.nlm.nih.gov/pmc/articles/PMC5153081/ 
10. Selmer C, Olesen JB, Hansen ML, Lindhardsen J, Olsen AM, Madsen JC, Faber J, Hansen PR, Pedersen $\mathrm{OD}$, Torp-Pedersen C, Gislason GH. The spectrum of thyroid disease and risk of new onset atrial fibrillation: a large population cohort study.BMJ. 2012; 345:e7895.

\section{Tables}

Table 1: ACSAF items. NT-proBNP: N-terminal fragment of brain natriuretic peptide prohormone, GFR: glomerular filtration rate

\begin{tabular}{|lr|}
\hline \multicolumn{2}{|l|}{ Ambulatory Care Score for Atrial Fibrillation (ACSAF) } \\
\hline Age $>75$ & 1 point \\
\hline Heart failure (NT-proBNP $>300 \mathrm{pg} / \mathrm{mL})$ & 1 point \\
\hline Acute coronary syndrome & 1 point \\
\hline Chronic kidney failure (GFR $<30 \mathrm{ml} / \mathrm{min})$ & 1 point \\
\hline Valvular AF & 1 point \\
\hline AF onset within the previous $48 \mathrm{~h}$ & 1 point \\
\hline Haemorrhagic risk with an indication for anticoagulation & 1 point \\
\hline Heart rate $<80$ or $>110$ after treatment with a beta-blocker & 1 point \\
\hline Associated pathology or triggering factor & 1 point \\
\hline
\end{tabular}

Table 2: Characteristics of the study population. TIA: transient ischaemic attack, ADL: activities of daily living, LVEF: left ventricular ejection fraction 


\begin{tabular}{|c|c|c|c|c|c|}
\hline \multirow{2}{*}{$\begin{array}{l}\text { Variables } \\
\text { Age (years) }\end{array}$} & \multicolumn{2}{|c|}{$\begin{array}{l}\text { Ambulatory care group } \\
\mathrm{n}=32\end{array}$} & \multicolumn{2}{|c|}{$\begin{array}{l}\text { Hospital care group } \\
\mathrm{n}=49\end{array}$} & \multirow{2}{*}{$\begin{array}{l}p \\
0.002\end{array}$} \\
\hline & $\begin{array}{l}62.6 \pm \\
15.0\end{array}$ & {$[57.2 ; 68.0]$} & $73.5 \pm 15.3$ & {$[69.1 ; 77.9]$} & \\
\hline Gender (man) & $21(65.6 \%)$ & {$[46.8 ; 80.8]$} & $21(42.9 \%)$ & {$[29.1 ; 57.7]$} & 0.08 \\
\hline \multicolumn{6}{|l|}{ Risk factors } \\
\hline Heart disease & $4(12.5 \%)$ & {$[4.1 ; 29.9]$} & $5(10.2 \%)$ & {$[3.8 ; 23.0]$} & 0.74 \\
\hline Hypertension & $16(50.0 \%)$ & {$[33.6 ; 66.4]$} & $27(55.1 \%)$ & {$[40.3 ; 69.1]$} & 0.82 \\
\hline Diabetes & $4(12.5 \%)$ & {$[4.1 ; 29.9]$} & $10(20.4 \%)$ & {$[10.7 ; 34.8]$} & 0.54 \\
\hline Stroke/TIA & $5(15.6 \%)$ & $[5.9 ; 33.5]]$ & $3(6.1 \%)$ & {$[1.6 ; 17.9]$} & 0.25 \\
\hline Tobacco use & $8(25.8 \%)$ & {$[12.1 ; 43.8]$} & $14(28.6 \%)$ & {$[17.0 ; 43.5]$} & 0.92 \\
\hline Chronic kidney failure & $2(6.2 \%)$ & {$[1.1 ; 22.2]$} & $5(10.2 \%)$ & {$[3.8 ; 23.0]$} & 0.7 \\
\hline \multicolumn{6}{|l|}{ Personal independence } \\
\hline Risk of falls & $1(3.1 \%)$ & {$[0.2 ; 18.0]$} & $14(28.6 \%)$ & {$[17.0 ; 43.5]$} & 0.010 \\
\hline ADL scale score & $\begin{array}{l}0.09 \pm \\
0.39\end{array}$ & {$[0.00 ; 0.23]$} & $0.57 \pm 1.63$ & {$[0.10 ; 1.04]$} & 0.054 \\
\hline Triggering factors & $13(40.6 \%)$ & {$[24.2 ; 59.2]$} & $32(27.2 \%)$ & {$[50.3 ; 77.9]$} & 0.051 \\
\hline \multicolumn{6}{|l|}{ Vital signs } \\
\hline Body temperature $\left({ }^{\circ} \mathrm{C}\right)$ & $36.4 \pm 0.9$ & {$[36.1 ; 36.7]$} & $36.9 \pm 1.0$ & {$[36.6 ; 37.2]$} & 0.012 \\
\hline Heart rate (bpm) & $103 \pm 32$ & {$[91 ; 115]$} & $97 \pm 33$ & {$[88 ; 107]$} & 0.43 \\
\hline Oxygen saturation (\%) & $99 \pm 3$ & {$[98 ; 99]$} & $97 \pm 3$ & {$[96 ; 98]$} & 0.004 \\
\hline \multicolumn{6}{|l|}{ Laboratory variables } \\
\hline Haemoglobin (g/dL) & $14.2 \pm 1.9$ & $\begin{array}{l}\text { [13.48; } \\
\text { 14.87] }\end{array}$ & $13.1 \pm 1.9$ & $\begin{array}{l}\text { [12.55; } \\
\text { 13.62] }\end{array}$ & 0.014 \\
\hline Leukocyte count (giga/L) & $8.3 \pm 3.2$ & {$[7.18 ; 9.50]$} & $10.8 \pm 5.0$ & {$[9.39 ; 12.24]$} & 0.008 \\
\hline $\mathrm{CRP}(\mathrm{mg} / \mathrm{L})(\mathrm{n}=80)$ & $30.3 \pm 63.6$ & {$[6.97 ; 53.60]$} & $53.7 \pm 71.5$ & $\begin{array}{l}\text { [33.18; } \\
\text { 74.27] }\end{array}$ & 0.13 \\
\hline Sodium (mEq/L) $(n=80)$ & $140.9 \pm 2.9$ & {$[140 ; 142]$} & $139 \pm 3.4$ & {$[138 ; 140]$} & 0.008 \\
\hline Potassium (mEq/L) $(n=80)$ & $4.1 \pm 0.4$ & {$[3.9 ; 4.2]$} & $4.1 \pm 0.5$ & {$[4.0 ; 4.3]$} & 0.6 \\
\hline Creatinine $(\mathrm{mg} / \mathrm{L})(\mathrm{n}=80)$ & $12.5 \pm 18.3$ & {$[5.8 ; 19.3]$} & $10.9 \pm 4$ & {$[9.7 ; 12.0]$} & 0.62 \\
\hline $\begin{array}{l}\text { NT pro-BNP }(\mathrm{pg} / \mathrm{mL}) \\
(\mathrm{n}=80)\end{array}$ & $881 \pm 1275$ & {$[1903 ; 3997]$} & $\begin{array}{l}4249 \\
\pm 5118\end{array}$ & {$[2674 ; 5824]$} & $<0.001$ \\
\hline
\end{tabular}




\begin{tabular}{|lcllll|}
\hline TSH $(\mathrm{mlU} / \mathrm{L})(\mathrm{n}=76)$ & $1.12 \pm 0.91$ & {$[0.78 ; 1.46]$} & $1.73 \pm 1.26$ & {$[1.36 ; 2.11]$} & 0.017 \\
\hline \multicolumn{2}{|l}{ Cardiologist's opinion/ transthoracic echocardiography } & & & \\
\hline LVEF $(\mathrm{n}=70)$ & $58 \pm 7.9$ & {$[55 ; 61]$} & $49 \pm 16.6$ & {$[44 ; 54]$} & 0.0034 \\
\hline Poor contractility & $0(0 \%)$ & {$[0 ; 16.0]$} & $8(19.0 \%)$ & {$[9.1 ; 34.6]$} & 0.048 \\
\hline Valvulopathy & $10(35.7 \%)$ & {$[19.3 ; 55.9]$} & $17(40.5 \%)$ & {$[26.0 ; 56.7]$} & 0.88 \\
\hline Dilatation & $11(40.7 \%)$ & {$[23.0 ; 61.0]$} & $26(60.5 \%)$ & {$[44.5 ; 74.6]$} & 0.17 \\
\hline Scores & & & & & \\
\hline CHA $_{2}$ DS2 VASc score ${ }^{32}$ & $17(53.1 \%)$ & {$[35.0 ; 70.5]$} & $39(83.0 \%)$ & {$[68.7 ; 70.5]$} & 0.009 \\
\hline HAS-BLED score >3 & $3(9.4 \%)$ & {$[2.5 ; 26.2]$} & $3(6.1 \%)$ & {$[1.6 ; 17.9]$} & 0.68 \\
\hline ACSAF & $1.03 \pm 0.97$ & {$[0.68 ; 1.38]$} & $2.16 \pm 1.05$ & {$[1.86 ; 2.46]$} & $<0.0001$ \\
\hline
\end{tabular}

Table 3: The sensitivity and specificity of each ACSAF cut-off value, together with the $95 \% \mathrm{Cls}$.

\begin{tabular}{lll} 
ACSAF & Sensitivity [95\%Cl] & Specificity [95\% Cl] \\
\hline 0 & $100[100-100]$ & $0[0-0]$ \\
1 & $97.96[93.88-100]$ & $28.12[12.50-28.12]$ \\
2 & $71.43[57.14-83.67]$ & $\mathbf{8 1 . 2 5}[68.75-93.75]$ \\
3 & $34.69[22.45-48.98]$ & $90.62[81.25-100]$ \\
4 & $10.2[2.04-20.41]$ & $96.88[90.62-100]$ \\
5 & $2.04[0-6.12]$ & $100[100-100]$ \\
6 & $0[0-0]$ & $100[100-100]$
\end{tabular}

\section{Figures}




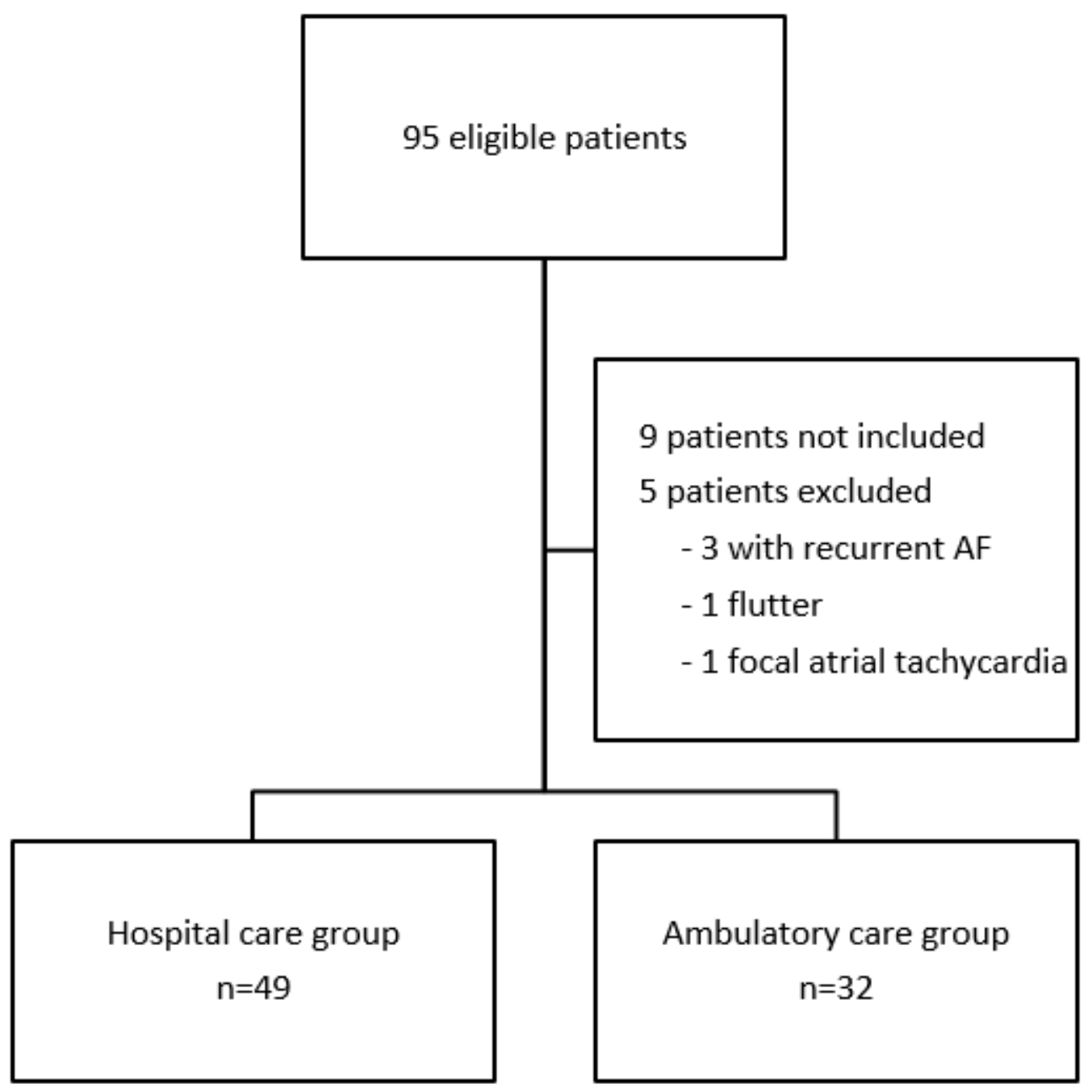

Figure 1

Study flow chart 


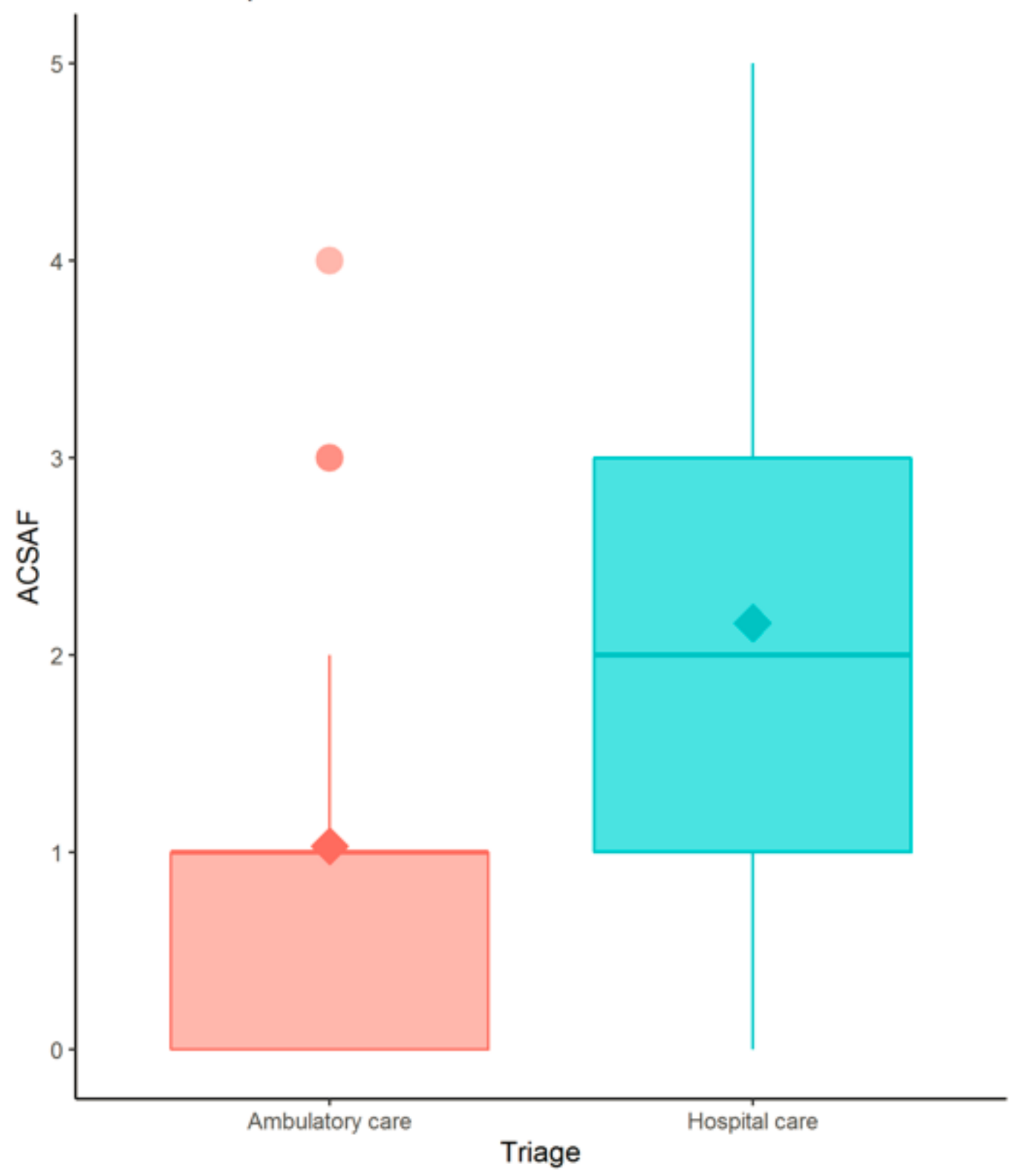

Triage

Ambulatory care

Hospital care

Figure 2

Legend not included with this version. 


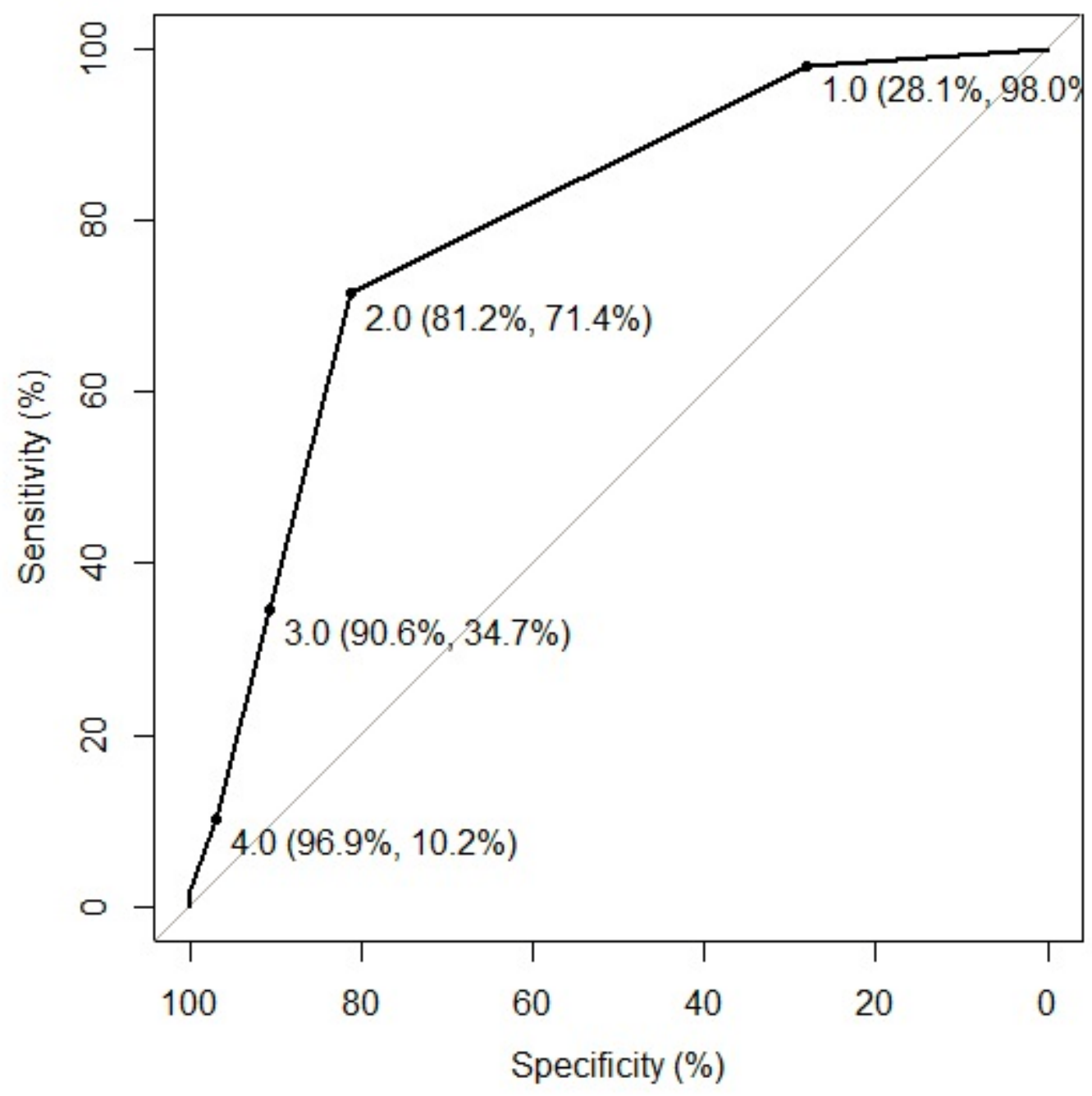

Figure 3

Legend not included with this version. 